\title{
RECONTEXTUALIZAÇÃO DE NÚMEROS RACIONAIS A PARTIR DE UMA DISCIPLINA DE ANÁLISE MATEMÁTICA PARA A EDUCAÇÃO BÁSICA
}

\author{
Jaqueline de Souza Pereira Grilo \\ Universidade Estadual de Feira de Santana \\ jspgrilo@uefs.br \\ Marcos Grilo \\ Universidade Estadual de Feira de Santana \\ grilo@uefs.br \\ Flávia Cristina de Mâcedo Santana \\ Universidade Estadual de Feira de Santana \\ Flaviacris.uefs@gmail.com
}

\section{Resumo}

A pesquisa teve como objetivo identificar como licenciandos transformam o conteúdo "Números Racionais" para fins de ensino na Educação Básica a partir de tópicos da disciplina Análise Matemática. Tomando como aporte teórico o conceito de recontextualização pedagógica de Basil Bernstein, este trabalho foi desenvolvido em uma turma de Análise Matemática de um curso de Licenciatura em Matemática e utilizou pressupostos da pesquisa qualitativa. Como procedimento de produção de dados recorreu-se à observação e análise da produção escrita dos licenciandos. Os resultados alcançados apontam que as recontextualizações propostas pelos licenciandos podem potencializar o ensino de Números Racionais na Educação Básica quando: identificam que tópicos vistos na formação inicial são possíveis de serem transformados para fins de ensino na educação básica; transformam textos produzidos na disciplina Análise Matemática para fins de ensino na educação básica; transformam textos dos livros didáticos fornecendo definições mais rigorosas, sem torná-las incompreensíveis.

Palavras-chave: Números Racionais; ensino; Análise Matemática; Recontextualização.

\begin{abstract}
The research had as objective to identify how teacher's in training initial transform the content "Rational Numbers" by the for purposes of teaching in Basic Education from topics of the Mathematical Analysis discipline. Taking as theoretical contribution the concept of pedagogical recontextualization of Basil Bernstein, this work was developed in a Mathematical Analysis class of a course of Degree in Mathematics and used assumptions of the qualitative research. As a data production procedure, it was used the observation and analysis of the written production of the teacher in initial formation. The results show that the recontextualization proposed by the future teachers can potentiate the teaching of Rational Numbers in Basic Education when: they identify that the subjects seen in initial formation can be transformed for didactic purposes in basic education; they transform texts produced in the Mathematical Analysis discipline for teaching purposes in basic education; they transform textbook textbooks by providing more stringent definitions without making them incomprehensible.
\end{abstract}

Keywords: Rational Numbers; teaching; Mathematical Analysis; Recontextualization. 


\section{INTRODUÇÃO}

Estudos na área de Educação Matemática têm investigado o papel da disciplina Análise Matemática em cursos de Licenciatura em Matemática (OTERO-GARCIA; BARONI; MARTINES, 2013; GOMES ET. AL, 2015; MOREIRA; VIANNA, 2016). Em geral, esses estudos têm analisado planos de curso com ênfase nos objetivos, ementa e bibliografia indicada ou, ainda, recorrem a entrevistas com coordenadores de cursos e professores que ministram a disciplina.

Martines (2012) entrevistou coordenadores de curso e professores que ministram Análise Matemática na Licenciatura em Matemática, a fim de identificar como eles compreendem o papel dessa disciplina na formação inicial de professores. O seu estudo apontou que, segundo os entrevistados, o papel da disciplina é fundamentar, consolidar e aprofundar o conhecimento matemático do futuro professor. Moreira e Vianna (2016), ao traçarem um paralelo entre as opiniões de matemáticos e educadores matemáticos sobre o papel da disciplina na Licenciatura em Matemática, encontraram resultado similar ao de Martines (2012). Ademais, os autores destacam que "o conjunto dos números reais foi um assunto de destaque nas entrevistas, sendo usado frequentemente como um exemplo da relação entre a disciplina de análise e a prática docente" (MOREIRA; VIANNA, 2016, p. 711).

A fundamentação teórica dos conjuntos numéricos IN, Z, Q e IR constitui-se em uma cadeia na qual constrói-se um conjunto a partir de outro cujas propriedades são previamente conhecidas. Uma vez admitida a existência dos números racionais e as propriedades da adição, multiplicação e relação de ordem, pode-se construir o conjunto dos números reais via cortes de Dedekind ou a partir do método de Cantor que utiliza sequências de Cauchy. $\mathrm{O}$ conjunto dos números racionais pode ser construído a partir do conjunto dos números inteiros e este, a partir do conjunto dos números naturais e os axiomas de Peano.

Entretanto, é pertinente questionar até que ponto esse conhecimento matemático visto no Ensino Superior contribui para a formação do professor de Matemática da Educação Básica. Moreira e David (2010) afirmam que a construção dos números racionais na Matemática escolar toma um caminho inverso da Matemática científica, em que, enquanto nesta busca-se a síntese da essência abstrata do conceito, naquela é fundamental explicitar as diferentes possibilidades de interpretação de um número racional. Neste sentido, Moreira e David (2010, p. 60) afirmam que a construção dos 
números racionais "pode ser considerada uma das mais complexas operações da Matemática escolar".

O estudo de Gomes et al. (2015, p. 1245) destaca que cabe ao professor "transformar seus conhecimentos [sobre Análise Matemática], em geral formais e rigorosos, em um conhecimento acessível a seus alunos (...), [pois] o futuro professor não aplicará diretamente em sua prática docente o que aprendeu na disciplina”. Entretanto, concordamos com Elias (2018, p. 441), quando o autor advoga que o problema da transformação do conteúdo matemático da Matemática científica para a Educação Básica "não pode ser resolvido facilitando a escrita de um texto matemático, como se a diferença entre o Bacharelado e a Licenciatura em Matemática fosse uma mera questão de simplificar o conteúdo".

Neste sentido, nos propomos a identificar como licenciandos transformam o conteúdo Números Racionais para fins de ensino na Educação Básica, a partir de tópicos da disciplina Análise Matemática.

\section{RECONTEXTUALIZAÇÃO PEDAGÓGICA DE TEXTOS}

Inspirados em Bernstein $(2000 ; 2003)$, podemos dizer que em salas de aula circulam textos que são produzidos tanto por professores quanto por alunos. Texto, no sentido bernsteiniano, expressa qualquer forma de representação pedagógica que pode ser apresentada de forma gestual, falada, visual, espacial, expressa pelo currículo, dentre outras. Neste caso, ao retomarmos o objetivo do estudo em tela, estamos interessados em identificar como licenciandos transformam textos produzidos na disciplina Análise Matemática de um curso de Licenciatura em Matemática, aqui representados pelos tópicos que versaram sobre Números Racionais, para fins de ensino na Educação Básica.

Para elucidar como um determinado texto é transformado desde o momento em que é criado até ser reproduzido, Bernstein $(2000 ; 2003)$ estruturou três campos: de produção, de recontextualização e de reprodução, que se relacionam hierarquicamente. Ou seja, não há reprodução de um determinado texto sem que haja recontextualização deste; do mesmo modo não há recontextualização sem que o texto tenha sido produzido.

Em linhas gerais, o campo de produção refere-se ao campo intelectual do sistema educacional; nele se dá a produção do texto por meio da criação ou modificação de novas ideias. Neste campo localizamos a Matemática científica. Sob um olhar bernsteiniano, diremos que a Matemática científica, representada neste estudo pela Análise Matemática, 
"é um discurso distinto, especializado, com seu próprio campo intelectual de textos, práticas, regras de entrada, modos de exame e princípios de distribuição de sucesso e privilégios" (BERNSTEIN, 2003, p. 156).

O processo de seleção de textos do campo de produção é realizado nos campos recontextualizadores que, de acordo com Bernstein (2000; 2003), podem ser de dois tipos: o oficial, formado pelo Estado e seus agentes; e o pedagógico, formado pelas universidades, por formadores de professor, por autores de livros, dentre outros. No contexto desta pesquisa, estamos interessados no processo de transformação de textos efetuado no campo de recontextualização pedagógica (CRP) aqui representado por um curso de Licenciatura em Matemática.

A principal atividade desse campo é apropriar-se de textos do campo de produção para transformá-los e, por meio de uma apropriação seletiva, relocá-los e relacioná-los a outros textos de diferentes contextos. Ao ser deslocado de um contexto a outro, por exemplo da Universidade para as escolas, o texto está sujeito a um novo posicionamento ideológico que cria, mantém, muda ou legitima o texto segundo as regras da prática pedagógica. Toda prática pedagógica, segundo Bernstein (2003), é uma relação social que visa a produção ou reprodução cultural. No contexto educacional, uma prática pedagógica possível é a relação social estabelecida entre professores e alunos.

Face ao exposto, é possível afirmar que textos sobre Análise Matemática, ao serem movidos para as aulas de Matemática na Educação Básica, e até mesmo no Ensino Superior, sofrem modificações que não permitem mais serem igualados aos textos originais. Sendo assim, compreendemos a Matemática escolar como um texto a ser transmitido e adquirido na prática pedagógica constituído a partir de um princípio recontextualizador que integra textos recontextualizados da Matemática científica, da Educação, do Estado, da família, da comunidade (GRILO; BARBOSA; LUNA, 2016).

O processo de recontextualização pedagógica estabelece que os professores transformam textos com base em outros princípios relacionados à aquisição/transmissão desses textos no contexto para o qual será destinado. $\mathrm{O}$ estudo desenvolvido por Grilo, Barbosa e Luna (2016) mostrou que durante o processo de recontextualização de textos de disciplinas da Licenciatura em Matemática, admite-se tanto o uso quanto a negação desses textos nas salas de aula da Educação Básica.

Segundo Bernstein (2003), os processos de transformações de um texto ocorrem primeiramente dentro dos campos recontextualizadores (oficial e pedagógico), seguido de uma outra transformação do texto já transformado, quando este se torna ativo no campo 
de reprodução. Aproximando esta afirmação da pesquisa que realizamos, diremos que a primeira transformação que textos sobre Análise Matemática sofrem é dentro do Curso de Licenciatura em Matemática, quando o mesmo é (ou pelo menos deveria ser) transformado para fins de formação do professor de Matemática. Já a segunda transformação ocorre quando esse texto já transformado se torna ativo nas salas de aula da Educação Básica, as quais associamos ao Campo de Reprodução. Ressaltamos que apesar da teoria utilizar a denominação "Campo de Reprodução", isso não significa dizer que este campo é apenas responsável por reproduzir textos, mas pode propor mudanças nas teorias, nas práticas e nos princípios que regulam os processos de recontextualização.

Face ao exposto, em termos teóricos, o objetivo da pesquisa foi identificar como licenciandos recontextualizam textos produzidos na disciplina Análise Matemática de um curso de Licenciatura em Matemática, aqui representados pelos tópicos que versaram sobre Números Racionais, para fins de ensino na Educação Básica.

\section{CONTEXTO DA PESQUISA}

A pesquisa foi desenvolvida em um Curso de Licenciatura em Matemática, em uma disciplina identificada neste trabalho como Análise Matemática. A ementa da disciplina contempla os Axiomas de Peano, a construção de conjuntos dos números inteiros, racionais e reais, enumerabilidade e limite de sequências de números reais. $\mathrm{O}$ Plano de Ensino da disciplina foi organizado conforme o modelo estabelecido pela Universidade.

A disciplina é oferecida no sexto semestre, onde espera-se que o aluno já tenha cursado Cálculo Diferencial e Integral, Equações Diferenciais, Cálculo de Funções de Várias Variáveis, Geometria Analítica, Geometria Euclidiana, Álgebra Linear, Teoria dos Números e Álgebra. A turma começou com 19 alunos matriculados dos quais 14 frequentaram até o final e 12 participaram da pesquisa.

O curso tratou de ideias fundamentais do pensamento matemático, essenciais para o professor da educação básica: definição por indução, definição por construção, demonstração por indução, demonstração por absurdo, classes de equivalência, aproximação e continuidade. Os conjuntos numéricos IN, Z, Q e IR, tópicos abordados no Ensino Fundamental, foram os objetos matemáticos estudados. Essa disciplina oportunizou ao discente compreender as relações entre números, o significado de operações e a importância de propriedades em situações cotidianas. Limite de sequências 
e uma introdução a tipos de infinito complementaram o componente curricular. Reflexões sobre possíveis recontextualizações na Educação Básica acompanharam a exposição de cada tópico, a fim de que o discente pudesse entender a importância do componente para a sua formação profissional.

\section{PROCEDIMENTOS METODOLÓGICOS}

Com o objetivo de identificar como os licenciandos recontextualizam o conteúdo Números Racionais na Educação Básica, a partir de tópicos do componente Análise Matemática, desenvolvemos uma pesquisa qualitativa, pois investigamos aspectos da vida social dificilmente quantificáveis, com o auxílio de constructos teóricos e com a utilização de diferentes instrumentos para analisar e interpretar os processos sociais que surgiram no contexto particular investigado (JUPP, 2006).

A atividade proposta foi composta de duas etapas, onde a turma se dividiu em equipes. Na primeira etapa, cada grupo deveria elaborar um texto, com 1 ou 2 páginas, discutindo como operariam a recontextualização pedagógica para a Educação Básica de um dos quatro tópicos elencados: a) números racionais - definição; b) números racionais - adição e propriedades; c) números racionais - multiplicação e propriedades; d) números racionais - relação de ordem. Na segunda etapa, cada grupo deveria apresentar oralmente as estratégias elencadas no texto elaborado.

Para a produção dos dados utilizamos a observação e a análise da produção escrita dos licenciandos. A observação foi utilizada com o intuito de obter informações sobre as possibilidades de recontextualização do texto matemático. O registro dos dados gerados por esse procedimento se deu mediante a utilização de gravador de áudio e vídeo. Identificamos que para a elaboração das estratégias, os licenciandos recorreram não só aos textos que circularam na disciplina Análise Matemática, mas os confrontaram com textos presentes em livros didáticos utilizados na Educação Básica. A produção escrita dos licenciandos juntamente com o diário de campo e a transcrição das filmagens, foram lidos e analisados a partir de conceitos da teoria dos códigos de Bernstein (2000; 2003).

Nesta investigação, tomamos como aporte metodológico para a análise dos dados as linguagens de descrição (interna e externa) propostas por Bernstein (2000). A linguagem de descrição interna caracteriza-se por ser uma linguagem conceitual, em nosso caso, o conceito de recontextualização pedagógica. A linguagem de descrição externa é constituída pelos dados empíricos. A articulação entre essas linguagens 
possibilita uma interlocução entre teoria e empiria, num movimento cíclico, que conforme Luna, Santana e Bortoloti (2018), os dados empíricos podem ampliar o debate teórico ou retroalimentá-lo, promovendo um diálogo entre a empiria e a teoria.

\section{APRESENTAÇÃO DOS DADOS}

Nesta seção, apresentamos em três categorias como os licenciandos propuseram a recontextualização de textos sobre o conteúdo "Números Racionais" a partir de tópicos da disciplina Análise Matemática. As categorias foram estabelecidas seguindo os princípios da linguagem de descrição (BERNSTEIN, 2003) e foram intituladas como segue: ressignificando o conceito; compreendendo uma operação; comparando números racionais.

\section{Categoria 1 - Ressignificando o conceito}

O Quadro 1 apresenta um trecho do texto que norteou a apresentação do grupo que ficou responsável por discutir a definição de Números Racionais. Os licenciandos compararam a definição de Números Racionais apresentada em um livro didático e a que foi estudada na disciplina Análise Matemática.

Quadro 1 - Transcrição do texto produzido pelo grupo 1

O livro apresenta a seguinte definição de números racionais:

"Os números que podem ser representados por uma fração $\frac{a}{b}$, em que a e b são números inteiros e $\mathrm{b} \neq 0$, são chamados de números racionais"

Já a definição apresentada na disciplina de análise é a seguinte:

$$
\text { "Q }=\left\{\frac{a}{b} ; a, b \in Z, b \neq 0\right\} "
$$

O professor da disciplina introduz a definição acima dizendo que é a definição que mais aparece no ensino básico, onde verificamos que realmente acontece isso. Ao analisarmos diversos livros do ensino básico onde na maioria dos livros aparecem uma definição como a citada acima, pode-se perceber que a definição inicial apresentada pela disciplina de Análise I é mais resumida, utilizando mais símbolos matemáticos e sem palavras. Bem diferente da definição do livro analisado onde pode ser observada uma adaptação da definição vista na universidade; onde aparecem mais palavras e menos símbolos matemáticos, agindo assim como facilitador para a compreensão da definição. Com essas e outras características apresentadas pelo livro concluímos que o mesmo cumpre seu papel no processo de adaptação dos textos cabendo também ao professor ajudar nesse processo com as anotações e observações em sala, facilitando assim ainda mais esse processo.

\section{Fonte: Os autores}

Os discentes sinalizaram que a forma como o conceito foi apresentado no livro didático facilita a sua compreensão na Educação Básica por ter mais palavras e menos símbolos matemáticos. Os alunos concluíram que o livro didático cumpriu o seu papel no processo de recontextualização de textos da Matemática científica para a Matemática escolar. 
Entretanto, durante a apresentação, um dos pesquisadores, professor da disciplina, chamou a atenção dos licenciandos, ressalvando que a definição de Números Racionais explicada na disciplina difere da que eles apresentaram. O professor pontuou que durante o curso foi feita a construção dos Números Racionais a partir de classes de equivalência definidas em ZxZ*. Por exemplo, a classe de equivalência $\overline{(1,2)}$ é o conjunto de todos os pares ordenados que são equivalentes ao par $(1,2)$, a saber, o próprio $(1,2)$, o par $(2,4)$, $(3,6)$ dentre outros. Neste sentido, a fração $\frac{1}{2}$ pode ser entendida como o conjunto que contém todas as frações equivalentes a $\frac{1}{2}$, a saber, a própria fração $\frac{1}{2}$, a fração $\frac{2}{4}, \frac{3}{6}$ dentre outras.

Essa abordagem foi classificada pelo professor de definição por construção. Percebendo que a estratégia de recontextualização sugerida pelos licenciandos indicava a negação desse texto, o professor os indagou sobre como eles poderiam relacionar a técnica de definição de números racionais por construção vista na disciplina com a Educação Básica como se observa no episódio a seguir.

(01) Professor: O que eu quero perguntar a vocês é: vocês têm a definição que é por construção. Esqueçam a formalização. É possível trabalhar uma definição por construção na educação básica?

(02) Licenciando 1: Eu creio que sim, porque eu estou trabalhando em um viés mais investigativo. Agora, de que forma eu vou trabalhar com os números racionais eu ainda não pensei. Eu posso levar para eles construírem, eles mesmos, e depois eu apresento a definição formal.

(03) Professor: Vejam só um exemplo que eu vou dar a vocês aqui: a gente não viu classes de equivalência? Quando a gente fez a discussão, nós usamos essa notação aqui. [o professor vai até o quadro e registra:]

$$
\overline{(3,4)}=\{(3,4),(9,12),(-3,-4) \ldots\} \sim\left\{\frac{3}{4}, \frac{9}{12}, \frac{-3}{-4}, \ldots\right\}
$$

Então, o par $(3,4)$ representa a fração $\frac{3}{4}$, não é isso? Que é também qualquer fração equivalente a $\frac{3}{4}$.

(04) Licenciando 2: No ensino básico eu não consigo trabalhar isso aqui de forma construtiva.

(05) Licenciando 3: Oh professor, eu acho que o professor não deve ficar preso ao livro didático. Por exemplo, ele pode trazer um material concreto para que o aluno perceba que, por exemplo, $\frac{1}{2}=\frac{2}{4}$ e assim por diante. Então, ele vai entender que são equivalentes.

(05) Pesquisador 1: Quando vocês ouviram o professor falar de classes de equivalência e vocês viram no quadro o que ele colocou aí, vocês associaram a algum conteúdo da educação básica?

[Os alunos respondem negativamente com a cabeça]

Não? Ninguém?

(06) Licenciandos: Não.

Mesmo com a tentativa do professor de levar os estudantes a refletirem sobre a recontextualização da definição por construção para fins de uso na Educação Básica, 
percebe-se no episódio acima que os licenciandos apresentam dificuldade em perceber que as frações equivalentes vistas na Matemática escolar são resultado de uma recontextualização das classes de equivalência estudadas na Matemática científica. A fundamentação teórica advinda da definição por construção dos números racionais refletirá na formação do professor desde que haja uma aproximação entre o campo de recontextualização pedagógica e o campo de reprodução. Destacamos que essa aproximação entre os campos pode favorecer a recontextualização de textos que circulam nos cursos de formação inicial, mesmo quando estes não são explícitos nos livros didáticos utilizados na Educação Básica.

\section{Categoria 2 - Compreendendo uma operação}

Os licenciandos discutiram a definição de adição de Números Racionais a partir da definição apresentada na disciplina Análise Matemática confrontando-a com as definições apresentadas em dois livros didáticos como se observa no Quadro 2.

Quadro 2 - Transcrição do texto produzido pelo grupo 2

O professor definiu da seguinte forma:

$$
\frac{a}{b}+\frac{c}{d}=\frac{a \cdot d+b \cdot c}{b \cdot d}
$$

E faz uma indagação: "Se definirmos:

$\frac{a}{b}+\frac{c}{d}=\frac{\frac{a \cdot m}{b}+\frac{c \cdot m}{d}}{m}$, onde $m=m m c(b, d)$. Quais as implicações?"

Outros livros didáticos que consultamos, traziam a frase tradicional "multiplique o mmc pelo numerador e divida pelo denominador" e de acordo com as experiências em sala de aula do grupo, percebemos que os alunos possuem dificuldades com este método.

Após as discussões sobre como abordar este conteúdo no ensino básico, criamos uma situação a qual estava bem presente no cotidiano dos nossos alunos. A pergunta norteadora seria: Como somar algo diferente? Onde iremos fazer referência aos denominadores da fração em questão. Como exemplos trouxemos: como somar $2 / 3$ de uma pizza com 1/4 dela, sendo que dividimos por 3 e no outro momento por 4. É possível somar? Sim, não e por quê? E daí partimos para a ideia de frações equivalentes e de como dividir a pizza de forma que pudéssemos somar 1/4 com 2/3.

No primeiro momento usaremos a questão norteadora para apresentarmos o conteúdo e em seguida a revisão sobre frações equivalentes. Logo após, a definição apresentada na disciplina de Análise- I M, mostrando que os dois métodos são similares e deixando o aluno a vontade para resolver as questões da forma que se sentir mais confortável.

Fonte: Os autores.

Avaliando que os alunos da Educação Básica possuem dificuldades em entender este método de somar números racionais, os licenciandos propuseram a recontextualização da técnica a partir de uma situação presente no cotidiano dos alunos da Educação Básica. Neste caso, os licenciandos propuseram a recontextualização de um 
tópico da disciplina Análise Matemática, negando a recontextualização apresentada nos livros didáticos. Além disso, a aproximação entre os campos de recontextualização e de reprodução permitiu que os mesmos não só identificassem os textos da disciplina Análise Matemática na Educação Básica como também propusessem uma estratégia baseada na definição de adição vista na disciplina tornando-a visível para os alunos da Educação Básica.

\section{Categoria 3 - Comparando números racionais}

Nesta categoria, identificamos que a proposta de recontextualização operada pelos licenciandos nega o texto sobre a relação de ordem entre Números Racionais apresentado no livro didático conforme se verifica no Quadro 3.

Quadro 3 - Transcrição do texto produzido pelo grupo 3

Neste capítulo, define-se que:

"Dado dois números racionais quaisquer, o menor deles será aquele que estiver à esquerda do outro na reta numérica".

Observe que não há, por parte do autor, uma definição clara sobre desigualdades de números racionais, ele a restringe a representação na reta numérica, o que pode criar obstáculos na aprendizagem do aluno. Uma restrição como essa nos faz ter alguns questionamentos e um deles é: de como o aluno faria para verificar a desigualdade de números racionais se uma reta numérica não estivesse sendo representada? Ele faria a representação? E se fossem números consideravelmente grandes, ainda assim fariam essa representação? Iriam transformar sempre os números em decimal para compará-los? Enfim, obstáculos como esse tendem a aparecer quando uma relação é definida de forma tão vaga.

Como visto na disciplina de Análise I-M, define-se relação de ordem da seguinte forma:

Sejam $a, b, c, d>0$

$$
\begin{gathered}
\text { (i) } \frac{a}{b} \leq \frac{c}{d}:=a d \leq c b \\
\text { (ii) } \frac{a}{b}<\frac{c}{d}:=\frac{a}{b} \leq \frac{c}{d} \text { e } \frac{a}{b} \neq \frac{c}{d} \\
\text { (iii) } \frac{a}{b}>\frac{c}{d}:=\frac{c}{d}<\frac{a}{b}
\end{gathered}
$$

Perceba que trata-se de uma definição mais consistente, onde o aluno não mais estará preso a uma representação geométrica, as condições de desigualdade estão agora explícitas, claras.

Quando pensamos na recontextualização para a Educação Básica, vimos que é possível levar para os alunos a definição abordada na disciplina de Análise. Porém, o recontextualizar se dará na linguagem utilizada pelo professor. Vale lembrar, que até aqui devemos considerar que o aluno não teve um contato com a álgebra, e é essa também uma oportunidade de aproximá-los dessa área do conhecimento.

Reconhecemos que a presença das letras já poderá criar uma barreira no ensino e aprendizagem e é aqui que a abordagem do professor será primordial. Deixar claro para o aluno quem é "a", quem é "b", quem é "c" e quem é "d" nessa definição é fundamental, deixar claro para eles que essas podem ser quaisquer letras também. Entender a presença das letras em matemática e qual a sua função não é algo que devemos esperar que vá partir do aluno, até aqui, com base em tudo que foi proposto para eles, o seu pensar matemático não está aguçado para isso, deverá o professor mediar essa compreensão. Exemplos numéricos também serão necessários para que os mesmos compreendam de forma mais visível tal definição.

Fonte: Os autores. 
Os licenciandos sinalizaram a ausência no livro didático de uma definição clara sobre a desigualdade entre Números Racionais e consideraram que a definição vista na disciplina Análise Matemática explicita rigorosamente as condições de desigualdade não dependendo da reta numérica. Contudo, os licenciandos ressaltaram a necessidade de transformar o texto da disciplina Análise Matemática tornando-o mais acessível aos alunos e deram pistas de que fariam isso a partir de exemplos numéricos.

Durante a apresentação, os licenciandos revelaram que tiveram dificuldades em propor uma recontextualização do texto da disciplina Análise Matemática para a Educação Básica, apesar de reconhecerem que o mesmo estará sujeito às regras de circulação do texto na Educação Básica como se observa no episódio a seguir.

(01) Licenciando 5: Olhando a definição do livro, a gente achou isso absurdo, porque restringe muito o pensamento do aluno. Não que não seja importante tratar da reta numérica para que ele perceba a relação, mas e o pensar matemático?

(04) Licenciando 4: Quando a gente foi analisar em como levar isso para a Educação Básica, a gente pensou que poderia organizar com menos precisão. Não menos precisão matemática, mas com menos formalização.

(05) Licenciando 5: Eu poderia dar isso aqui [aponta para a definição vista na disciplina Análise Matemática] numérico, mas será que quando eu faço isso eu estou desenvolvendo o pensamento matemático do estudante? Por que a gente aprende aqui que uma ideia matemática só vale se a generalização dela for verdadeira.

(06) Licenciando 4: Toda vez que a gente pensava em fazer algo diferente a gente encontrava uma dificuldade.

(07) Licenciando 5: Na verdade, é assim: a gente só teve contato agora, no sexto semestre, com pegar isso aqui [aponta para a definição vista na disciplina Análise Matemática] para levar pra lá [Educação Básica].

(08) Licenciando 4: E a gente não queria restringir o aluno.

(09) Professor: A grande dificuldade que vejo no ensino de Matemática hoje é que a gente só ensina a linguagem e não as ideias matemáticas. Se você for olhar ali [refere-se às definições apresentadas pelo grupo] mesmo sendo símbolo ou não, o importante é discutir qual a ideia que está por trás.

O episódio acima destaca a necessidade de aproximar, cada vez mais, o campo de recontextualização ao campo de reprodução afim de possibilitar que os licenciandos reflitam sobre como textos que circulam em disciplinas como Análise Matemática podem ser recontextualizados para a Educação Básica. Apesar da dificuldade em explicitar como fariam a transformação do texto da disciplina, ficou clara a importância da mesma no processo de recontextualização do texto do livro didático e para a incorporação de seus textos, mesmo que com poucas transformações, na Matemática escolar. 


\section{CONSIDERAÇÕES FINAIS}

Com base no que foi exposto identificamos que as recontextualizações propostas pelos licenciandos podem potencializar o ensino de Números Racionais na Educação Básica quando: identificam que tópicos vistos na formação inicial são possíveis de serem transformados para fins de ensino na Educação Básica, como mostrou a Categoria 1; transformam textos produzidos na disciplina Análise Matemática para fins de ensino, como vimos nas Categoria 2; propõem a transformação de textos de livros didáticos fornecendo definições mais rigorosas, conforme Categoria 3, sem torná-las incompreensíveis. Ao contrário, tornando-as, inclusive, mais atrativas para os alunos (conforme Categoria 2).

Identificamos que um texto da Matemática científica pode ser inicialmente negado no processo de recontextualização pedagógica, como vimos na Categoria 1, pois este não é visível nos guias curriculares da Matemática escolar. Entretanto, a aproximação entre o campo de recontextualização pedagógica e o campo de reprodução pode favorecer a associação de um texto da Matemática científica com outros textos já transformados em livros didáticos. Por outro lado, também verificamos que textos da Matemática científica podem subsidiar o processo de recontextualização de textos que são apresentados nos livros didáticos.

Por fim, registramos que as análises empreendidas pelos licenciandos sobre os livros didáticos, apoiados pelos textos que circularam na disciplina Análise Matemática, demonstraram a importância dessa disciplina nos cursos de formação inicial de professores. Feito esse registro, convidamos mais professores de disciplinas que tratam da Matemática científica nos cursos de Licenciatura em Matemática a fazerem esse exercício de aproximação com a Matemática escolar, haja vista que esta pode potencializar o trabalho do professor de Matemática da Educação Básica.

\section{REFERÊNCIAS}

BERNSTEIN, Basil. Class, codes and control: The structuring of pedagogic discourse. New York: Routledge, 2003.

BERNSTEIN, Basil. Pedagogy, symbolic control and identity: Theory, research, critique. New York: Rowman \& Littlefield, 2000.

ELIAS, Henrique Rizek. Os Números Racionais na Matemática Acadêmica: uma discussão visando à formação matemática de professores. Bolema, Rio Claro, v. 32, n. 61, p. 439-458, ago. 2018. Disponível em: 
$<\underline{\text { http://www.scielo.br/scielo.php?script }=\text { sci arttext\&pid }=\mathrm{S} 0103-}$

636X201800020043\&lng=en\&nrm=iso >. Acesso em: 29 set. 2018.

GOMES, Danilo Olímpio et al. Quatro ou Mais Pontos de Vista sobre o Ensino de Análise Matemática. Bolema, Rio Claro, v. 29, n. 53, p. 1242-1267, Dez. 2015. Disponível em: $<$ http://www.scielo.br/scielo.php?script $=$ sci arttext\&pid $=$ S0103-

636X2015000301242\&lng=en\&nrm=iso >. Acesso em: 05 out. 2018.

GRILO, Jaqueline de S. P.; BARBOSA, Jonei C.; LUNA, Ana V. de A. A recontextualização de textos de disciplinas específicas da Licenciatura em Matemática para a educação básica. Acta Scientiae, v. 18, n. 2, p. 251-273, maio/ago. 2016. Disponível em: $<$ http://www.periodicos.ulbra.br/index.php/acta/article/view/1184/1608>. Acesso em: 04 out. 2018.

JUPP, Victor. The Sage Dictionary of Social Research Methods. Thousand Oaks: Sage, 2006.

LUNA, Ana V. A.; SANTANA, Flávia C. de M.; BORTOLOTI, Roberta D. M.. A linguagem de descrição: uma possibilidade de fazer pesquisas no campo da educação matemática. Educ. Mat. Pesq., [S.1.], v. 20, n. 1, maio 2018. Disponível em:

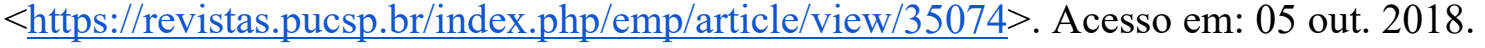

MARTINES, Paula T. O papel da disciplina de Análise segundo professores e coordenadores. 2012, 117 p. Dissertação (Mestrado em Educação Matemática) Universidade Estadual Paulista Júlio de Mesquita Filho, Rio Claro, São Paulo, 2012.

MOREIRA, Plínio C.; DAVID, Maria M. M. S.. Números racionais: conhecimentos da formação inicial e prática docente na escola básica. Bolema, Rio Claro, v. 17, n. 21, p. 119, mai. 2004. Disponível em: $<\underline{\text { http://www.periodicos.rc.biblioteca.unesp.br/index.php/bolema/article/view/10534/69 }}$ 40>. Acesso em: 01 out. 2018.

MOREIRA, Plínio C.; DAVID, Maria M. M. S. A formação matemática do professor: licenciatura e prática docente escolar. 2 ed. Belo Horizonte: Autêntica, 2010.

MOREIRA, Plínio C.; VIANNA, Carlos R. Por Que Análise Real na Licenciatura? Um Paralelo entre as Visões de Educadores Matemáticos e de Matemáticos. Bolema, Rio Claro, v. 30, n. 55, p. 515 - 534, ago. 2016. Disponível em: $<$ http://www.scielo.br/scielo.php?script=sci_arttext\&pid=S0103636X2016000200515\&lng=pt\&nrm=iso> . Acesso em: 05 out. 2018.

OTERO-GARCIA, Sílvio C.; BARONI, Rosa L. S.; MARTINES, Paula T. Uma trajetória da disciplina de Análise e o seu papel para a formação do professor de matemática. Educação Matemática Pesquisa : Revista do Programa de Estudos Pós-Graduados em Educação Matemática, [S.1.], v. 15, n. 3, p. 692-717, dez. 2013. Disponível em: $<$ https://revistas.pucsp.br/index.php/emp/article/view/16756>. Acesso em: 05 out. 2018.

Submetido em 07 de outubro de 2018. Aprovado em 25 de março de 2019. 